\title{
CDISC SDTM Device-In-Use Test Name Terminology
}

National Cancer Institute

\section{Source}

National Cancer Institute. CDISC SDTM Device-In-Use Test Name Terminology. NCI Thesaurus. Code C106482.

Terminology associated with the device-in-use test name codelist of the Clinical Data Interchange Standards Consortium (CDISC) Study Data T abulation Model (SDT M). 